\title{
ANÁLISE ERGONÔMICA E BIOMECÂNICA DA COLHEITA DA RAÍZ DA MANDIOCA: ESTUDO DE CASO
}

\section{ERGONOMIC AND BIOMECHANICAL ANALYSIS OF THE CASSAVA ROOT HARVEST: CASE REPORT}

\author{
Eugenio A D Merino ${ }^{1}$, PhD.Sc \\ Lincoln da Silva ${ }^{2}$, M.Sc \\ Diego Luiz de Mattos ${ }^{3}$, M.Sc \\ Bruno Maia Guimaraes ${ }^{4}$, D.Sc \\ Noe Gomes Borges Junior ${ }^{5}$, PhD.Sc \\ Susana Cristina Domenech ${ }^{6}$, D.Sc \\ Giselle Schmidt A D Merino ${ }^{7}$, D.Sc \\ (1) Universidade Federal de Santa Catarina \\ e-mail: eugenio.merino@ufsc.br
}

(2) Universidade Federal de Santa Catarinae-mail: lincoln floripa@yahoo.com.br

(3) Universidade Federal de Santa Catarina e-mail:_diegoclerigo@yahoo.com.br

(4) Instituto Federal de Santa Catatina e-mail:bmguimaraes@gmail.com

(5) Universidade do Estado de Santa Catarina e-mail:nborgesjr@gmail.com

(6) Universidade do Estado de Santa Catarina e-mail: scdomenech@gmail.com

(7) Universidade Federal de Santa Catarina e-mail:gisellemerino@gmail.com 


\section{$16^{\circ}$ \\ ERGODESIGN USIHC CINAHPA}

$16^{\circ}$ Ergodesign - Congresso Internacional de Ergonomia e Usabilidade de Interfaces Humano Tecnológica: Produto, Informações Ambientes Construídos e Transporte

$16^{\circ}$ USIHC - Congresso Internacional de Ergonomia e Usabilidade de Interfaces Humano Computador

CINAHPA | 2017 - Congresso Internacional de Ambientes Hipermídia para Aprendizagem.

\section{Ergonomia; Mandioca; Biomecânica.}

Este estudo teve por fim identificar os riscos físicos inerentes a atividade de cultivo e arranque manual da mandioca em uma propriedade de agricultura familiar catarinense. Os métodos utilizados foram a dinamometria isométrica de extensão lombar em conjunto com a eletromiografia paravertebral no teste isométrico e no momento real do arranque da raiz da mandioca. Os resultados apresentam valores de força isométrica de extensão lombar adequados para idade e sexo e alteração eletromiográfica sugerindo mudança fisiológica e importante instauração de fadiga nos músculos multifidos. As conclusões indicam que as alterações teciduais apresentadas podem gerar danos graves sobre a musculatura estudada, o que afetaria o estado produtivo do indivíduo da pesquisa.

\section{Ergonomics; Cassava; Biomechanics}

This study aimed to identify the physical risks of the cultivation and manual grubbing of cassava in a family farm in Santa Catarina. The methods used were the isometric dynamometry of lumbar extension associated with the paravertebral electromyography in the isometric test and in the moment of removing of the cassava root. The results show isometric values of lumbar extension adequate for age and sex and electromyographic alteration suggesting physiological change and important fatigue instauration in the multifidus muscles. The conclusions indicate that the presented tissue alterations can generate serious damages on the studied musculature, which would affect the productive the productivity of the voluntary worker.

\section{Introdução}

Umas das atividades registradas pela produção rural brasileira é o cultivo da mandioca. A mandioca (Manihot esculenta Crantz) é uma cultura tropical largamente plantada e compõe a base energética da alimentação de mais de 800 milhões de pessoas no mundo, sobretudo nos países com menos recursos, como os do continente africano (FAO, 2013). Na safra de 2014/2015, o Brasil produziu aproximadamente 24 milhões de toneladas, correspondendo a $75 \%$ da produção da América do Sul, o que equivale ao total de 1,567.683,00 hectares de área plantada e rendimento de 148.257 hectograma/hectare (EMBRAPA, 2015).

Apesar da elevada produção desta cultura, poucos estudos têm sido realizados objetivando a melhoria dos sistemas produtivos e consequentemente das atividades que requerem maior esforço manual dos trabalhadores, e que muitas vezes levam a incapacidades para o trabalho, principalmente quando se trata de agricultura familiar (FERNANDES et al., 2014; CUNHA, MERINO e MERINO, 2015). As doenças musculoesqueléticas são as patologias mais comuns e onerosas na agricultura (KINKHOERN et al., 2010; FATHALLAH et al., 2008). Segundo dados da
Previdência Social, foram emitidos 12.817 auxílios acidentes de trabalho para trabalhadores rurais no ano de 2014, enquanto que os custos sucedidos da emissão desses benefícios foram de R $\$ 4.637 .000$ (BRASIL, 2015). O trabalho neste setor exige posturas inadequadas, manuseio de cargas e movimentos repetitivos, fatores reconhecidamente de risco para doenças musculoesqueléticas, principalmente na região lombar (FATHALLAH, 2010).

A convergência desses fatores delineados pela representatividade da agricultura familiar nacional e, mais especificamente, da produção de mandioca no estado de Santa Catarina, a natureza da realização das tarefas, as condições de trabalho do homem no campo que podem culminar no adoecimento do trabalhador e afastamento de suas atividades por lesões de natureza musculoesquelética, apontam para uma lacuna de conhecimentos que requer a compreensão das consequências físicas do trabalho rural. Diante do exposto, esta pesquisa teve como objetivo identificar os riscos físicos inerentes a atividade de extração manual das raízes de mandioca relacionado à região lombar.

\subsection{Caracterização Geral}

Esta pesquisa é caracterizada como de natureza 


\section{$16^{\circ}$ \\ ERGODESIGN USIHC CINAHPA}

aplicada, com uma abordagem quantitativa e qualitativa, descritiva e de natureza exploratória.

A amostra foi composta por um trabalhador do sexo masculino que realiza a etapa de extração manual das raízes de mandioca na propriedade. Os métodos utilizados para este estudo proporcionaram uma elevada quantidade de dados. Em função disso, não foi necessária uma amostra elevada de pessoas para efetividade destes métodos (DOUPHRATE et al., 2016).

A pesquisa foi aprovada pelo Comitê de Ética em Pesquisa da Universidade Federal de Santa Catarina sob parecer $n^{\circ}$ 05372012.9.0000.0121. O participante assinou o Termo de Consentimento Livre e Esclarecido (TCLE).

\subsection{Etapas}

O estudo foi dividido em três etapas:

Levantamento bibliográfico acerca da situação estudada; Coleta de dados in loco; Análise dos dados coletados.

\subsection{Materiais e Métodos}

A coleta de dados foi realizada utilizando a dinamometria de extensão lombar e a eletromiografia dos músculos multifidos.

\subsubsection{Dinamometria isométrica de extensão lombar}

$\mathrm{Na}$ dinamometria isométrica de extensão lombar, o indivíduo estava descalço, posicionado sobre a plataforma contendo uma célula de carga "S"(capacidade máxima de $200 \mathrm{~N}$ ) acoplada; permaneceu com a coluna ereta mantendo os braços estendidos em frente às coxas para fazer o posicionamento correto do puxador que seria tracionado. Na sequência, foi solicitado ao indivíduo a execução da flexão anterior de tronco (aproximadamente $140^{\circ}$ ), leve flexão de joelhos, e, segurando o puxador com as mãos, foi solicitado a execução da força máxima de tração no puxador, de forma perpendicular à plataforma, sem qualquer contato tanto do puxador como das mãos com qualquer outra parte do seu corpo. Foram coletados os valores máximos de três tentativas para fazer a $16^{\circ}$ Ergodesign - Congresso Internacional de Ergonomia e Usabilidade de Interfaces Humano Tecnológica: Produto, Informações Ambientes Construídos e Transporte

$16^{\circ}$ USIHC - Congresso Internacional de Ergonomia e Usabilidade de Interfaces Humano Computador

CINAHPA | 2017 - Congresso Internacional de Ambientes Hipermídia para Aprendizagem.

média aritmética do teste (SOARES, 2012; SOARES, 2013).

\subsubsection{Eletromiografia dos músculos multifidos}

A aquisição dos sinais de força e de eletromiografia (EMG) foi realizada com um eletromiógrafo de 4 canais Miotool 400 da marca Miotec. O sistema funciona com o software Miograph 2.0 USB, onde os dados são transmitidos para um computador portátil. Os sinais de força e de EMG foram coletados com uma taxa de amostragem de $1000 \mathrm{~Hz}$ para cada canal, filtro passa alta de $5 \mathrm{~Hz}$, filtro passa baixa de $500 \mathrm{~Hz}$ e filtro notch $60 \mathrm{~Hz}$, com taxa de aquisição de 2000 amostras/segundo por canal.

Para o registro do sinal eletromiográfico, foram utilizados pares de eletrodos de superfície de $\mathrm{Ag} / \mathrm{AgCl}$, pré-geleificado (Meditrace ${ }^{\circledR}$ ), em configuração bipolar, com área de captação de $1 \mathrm{~cm}$ de diâmetro e distância inter-eletrodos de $2 \mathrm{~cm}$, com adesivo de fixação. Os eletrodos foram posicionados nos músculos multifidos direito e esquerdo ao nível das vértebras lombares L4-L5. (BARBOSA; ALMEIDA; GONÇALVES, 2010), segundo as normas da SENIAM (HERMENS et al., 2002).

\section{Resultados}

A figura 1 ilustra o posicionamento do indivíduo durante a atividade analisada.

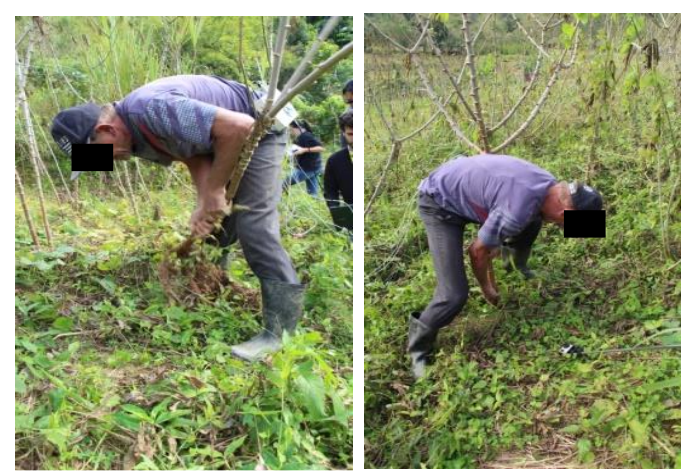

Figura 1: Postura adotada durante a atividade de arranque manual da mandioca.

\subsection{Dinamometria isométrica de extensão lombar}

Os resultados obtidos por meio da dinamometria 


\section{$16^{\circ}$ \\ ERGODESIGN USIHC CINAHPA}

permitiram identificar que em relação ao pico e a média de força isométrica de extensão lombar (Figura 2), houve maior diferença nos valores entre as coletas 1 e 2 do que entre as coletas 2 e 3 . O maior pico de força ocorreu na segunda coleta, enquanto que a maior média foi observada na terceira coleta (Tabela 1).

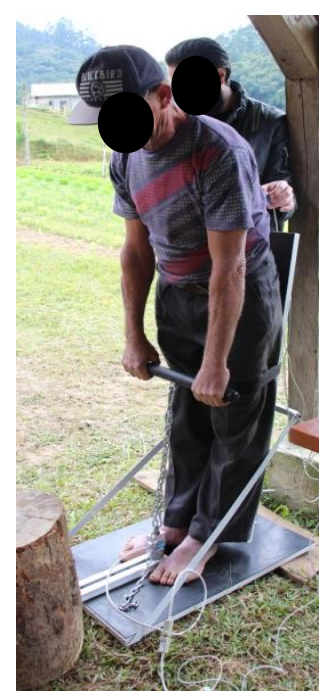

Figura 2: Ilustração do teste de dinamometria isométrica $16^{\circ}$ Ergodesign - Congresso Internacional de Ergonomia e Usabilidade de Interfaces Humano Tecnológica: Produto, Informações Ambientes Construídos e Transporte

$16^{\circ}$ USIHC - Congresso Internacional de Ergonomia e Usabilidade de Interfaces Humano Computador

CINAHPA | 2017 - Congresso Internacional de Ambientes Hipermídia para Aprendizagem. de extensão lombar (LABIN-UDESC)

\begin{tabular}{ccccc}
\hline & $\begin{array}{c}\text { Coleta 1 } \\
\text { (Kgf) }\end{array}$ & $\begin{array}{c}\text { Coleta } \\
\mathbf{2}(\text { Kgf) }\end{array}$ & $\begin{array}{c}\text { Coleta 3 } \\
(\text { Kgf) }\end{array}$ & Média \pm Desvio Padrão (DP) \\
\hline $\begin{array}{c}\text { Pico de } \\
\text { Força }\end{array}$ & 133,38 & 150,21 & 146,45 & $148,33 \pm 2.66$ \\
$\begin{array}{c}\text { Média de } \\
\text { Força }\end{array}$ & 113,55 & 124,17 & 126,24 & $121,32 \pm 6.81$ \\
\hline
\end{tabular}

Tabela 1: Pico e média de força isométrica de extensão lombar (kgf). Fonte: Os autores, 2017.

\subsection{Eletromiografia $(E M G)$}

O Gráfico 01 apresenta a produção de força do músculo multífido direito por meio do sinal eletromiográfico- RMS e a sua fadiga em função do tempo de desempenho, por meio da FM, na extração manual da mandioca. Também é demonstrada a linha de tendência de queda dos valores da FM e a respectiva equação linear. Podese evidenciar a tendência de perda de força e instauração da fadiga principalmente no momento (50 - 60) com base no aumento do sinal eletromiográfico- RMS $(177 \mu \mathrm{V})$ e concomitante diminuição nos valores da FM $(91 \mathrm{~Hz})$. 


\section{$16^{\circ}$ \\ ERGODESIGN USIHC CINAHPA}

$16^{\circ}$ Ergodesign - Congresso Internacional de Ergonomia e Usabilidade de Interfaces Humano Tecnológica: Produto, Informações Ambientes Construídos e Transporte

$16^{\circ}$ USIHC - Congresso Internacional de Ergonomia e Usabilidade de Interfaces Humano Computador

CINAHPA | 2017 - Congresso Internacional de Ambientes Hipermídia para Aprendizagem.

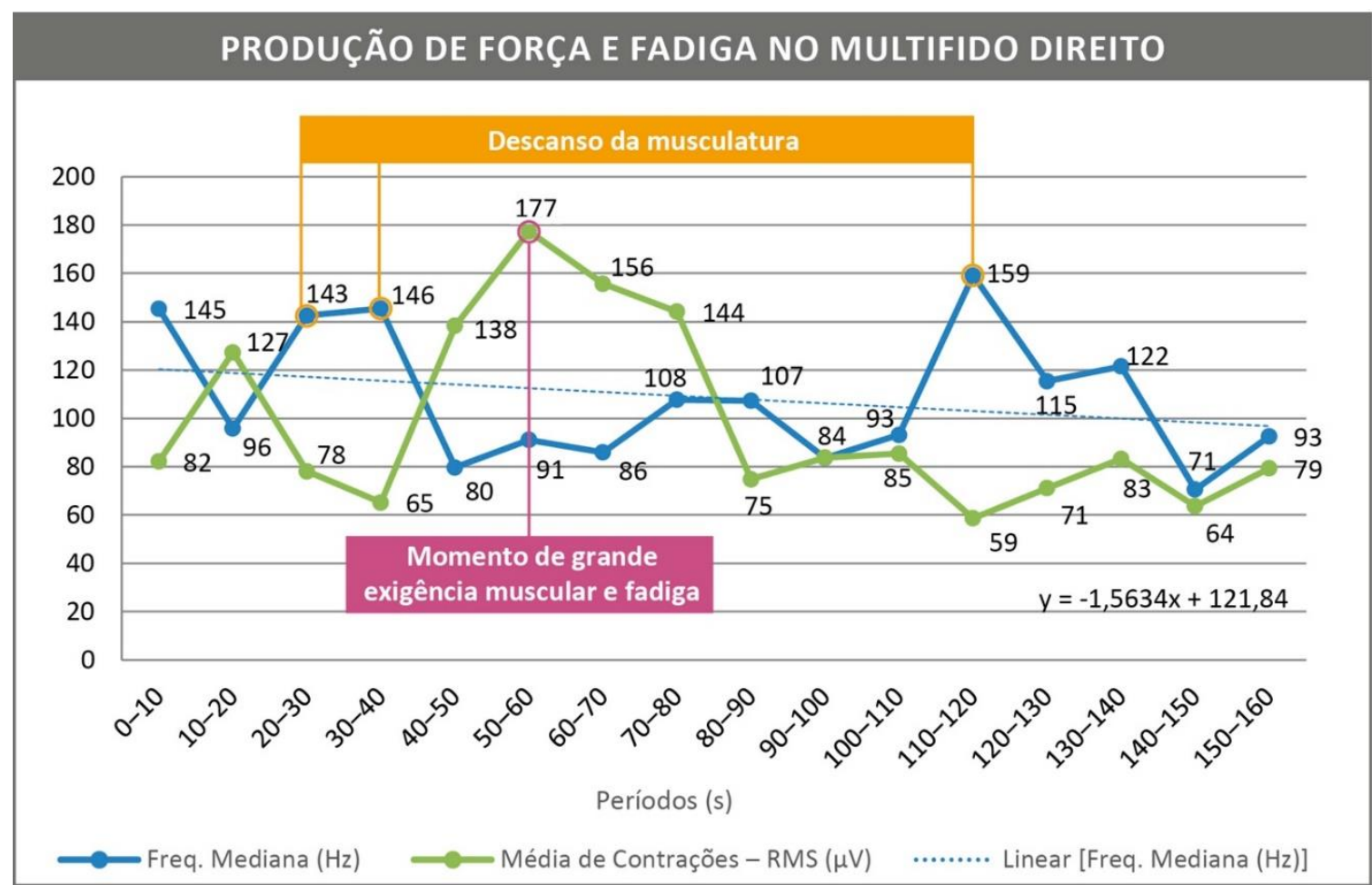

Gráfico 01: Produção de força do musculo multifido direito e sua fadiga em função do tempo na atividade de extração manual de mandioca. Fonte: Os autores, 2017

O Gráfico 02 apresenta a produção de força do músculo multífido esquerdo por meio do sinal eletromiográfico- RMS e a sua fadiga em função do tempo de desempenho, por meio da FM. Também é demonstrada a linha de tendência de queda dos valores da FM e a respectiva equação linear. Pode-se evidenciar a tendência de perda de força e instauração da fadiga principalmente nos momento [(60 - 70); (90-100); (110-120) e 150160)] com base no aumento do sinal eletromiográfico- RMS e concomitante diminuição nos valores da FM. 


\section{$16^{\circ}$ \\ ERGODESIGN \\ USIHC \\ CINAHPA}

$16^{\circ}$ Ergodesign - Congresso Internacional de Ergonomia e Usabilidade de Interfaces Humano Tecnológica: Produto, Informações Ambientes Construídos e Transporte

$16^{\circ}$ USIHC - Congresso Internacional de Ergonomia e Usabilidade de Interfaces Humano Computador

CINAHPA | 2017 - Congresso Internacional de Ambientes Hipermídia para Aprendizagem.

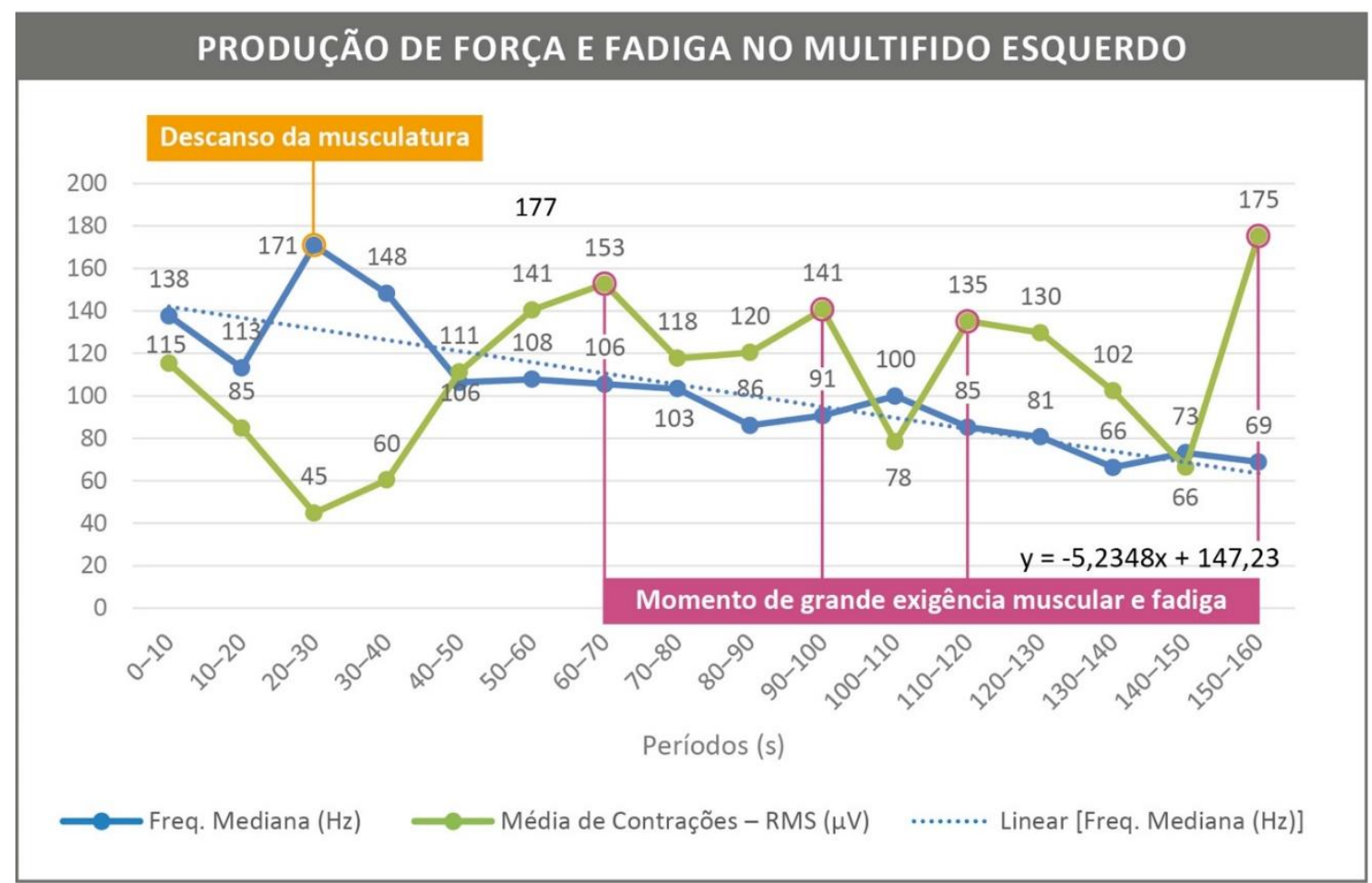

Gráfico 02: Produção de força do musculo multifido esquerdo e sua fadiga em função do tempo na atividade de extração manual de mandioca. Fonte: Os autores, 2017.

Ao comparar-se os gráficos 1 e 2, pode-se afirmar que houve maior instauração de fadiga no músculo multifido esquerdo, havendo pouca recuperação da FM em função do tempo nesse musculo.

O Gráfico 03 demonstra a média do percentual de esforço, em períodos de 10 segundos, dos músculos multífidos, normalizado pela média dos valores máximos de atividade eletromiográfica obtidos no teste de CIVM (Multífido Direito: $300,5 \mu \mathrm{V}$ e Multífido Esquerdo: $294,04 \mu \mathrm{V}$ ). Observa-se que o multífido esquerdo apresentou a média dos valores maior (54\%) quando comparado ao direito (47\%), demonstrando, assim, maior atividade paravertebral esquerda na sustentação dos movimentos de flexão e extensão do tronco. 
$16^{\circ}$ USIHC - Congresso Internacional de Ergonomia e Usabilidade de Interfaces Humano Computador

CINAHPA | 2017 - Congresso Internacional de Ambientes Hipermídia para Aprendizagem.

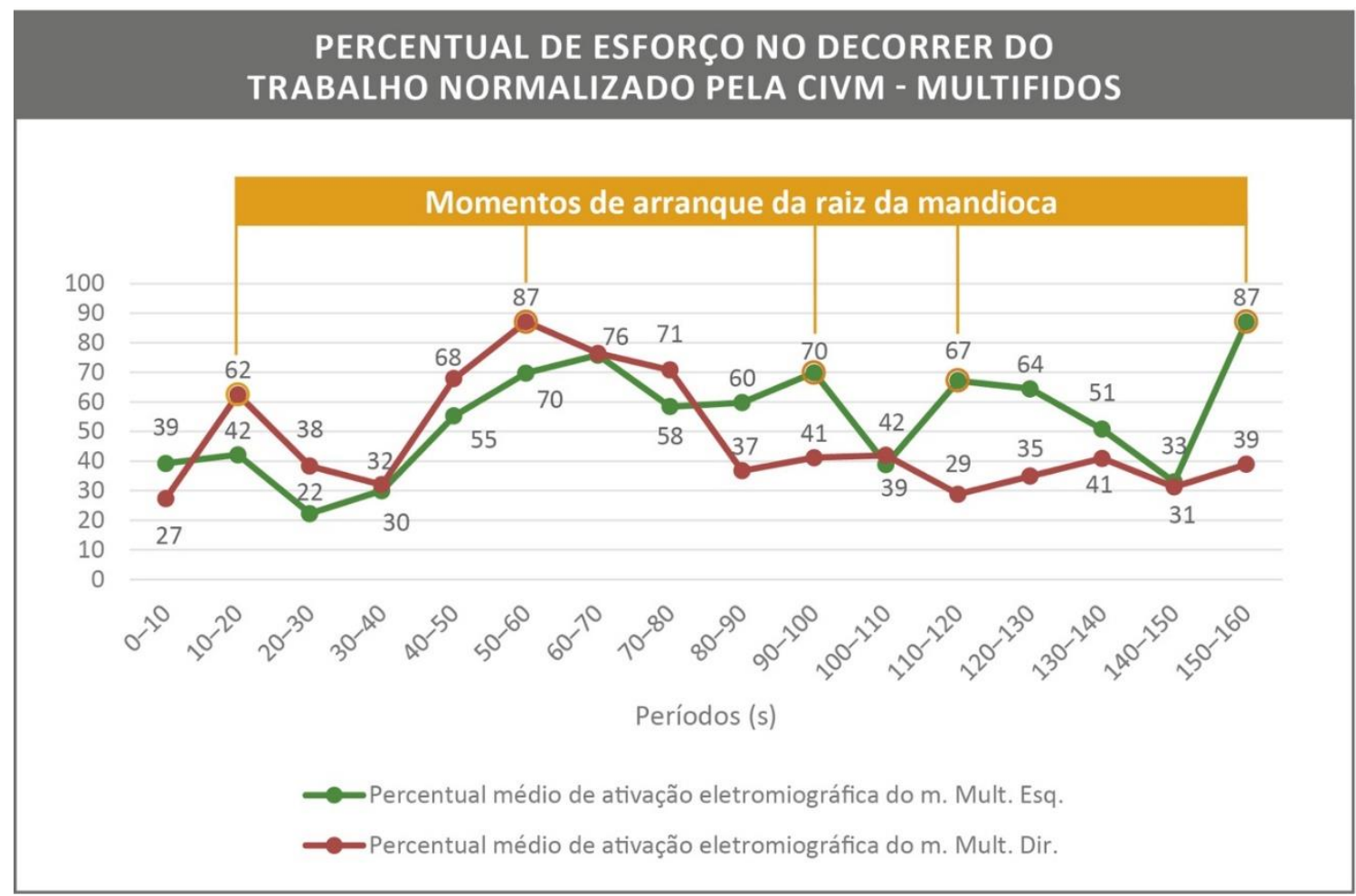

Gráfico 03: Percentual de esforço dos músculos multifidos em função do tempo, normalizado pelo teste CIVM. Fonte: Os autores, 2017.

\section{Discussão}

Em relação à coluna lombar, o risco de lesões musculoesqueléticas durante a extração manual das raízes de mandioca pode ser causado pela posição de trabalho em flexão de tronco, aumentando a sobrecarga nessa região, conforme alguns autores têm demonstrado (GALLAGHER et al., 2005; COSTA E VIEIRA, 2009; PRAIRIE et al., 2016). Além disso, o aumento de força na coluna lombar é capaz de causar lesões musculoesqueléticas na região (GALLAGHER E MARRAS, 2012; STAMBOLIAN et al., 2016).

A capacidade funcional de um indivíduo no meio laboral está diretamente relacionada a sua força muscular. Neste sentido, a dinamometria é a instrumentação mais utilizada para a avaliação da força muscular isométrica. Esta pode demonstrar a variação da força no decorrer do tempo (BORGES Jr, 2009).

Os achados na dinamometria muscular podem contribuir na avaliação admissional e periódica, sendo um meio de fundamental importância na estimativa da capacidade funcional do indivíduo no seu ambiente laboral (SOARES, 2012). Huijnen et al. (2013), também cita a dinamometria de extensão lombar como um teste que pode avaliar a capacidade funcional de indivíduos com lombalgia.

Os valores de força isométrica de extensão lombar máxima (Kgf) encontrados neste estudo são próximos aos encontrados por Soares et al.(2012), que obteve para homens saudáveis a média de pico de força isométrica de extensão lombar de $107 \pm 24$ Kgf e Soares et al.(2013) que obteve valores para homens saudáveis de $114 \pm 24,5 \mathrm{Kgf}$.

Porém, em relação à eletromiografia, observa-se que os valores obtidos nos dados coletados do sujeito de pesquisa aproximam-se da referência para pessoa com diagnóstico de lombalgia crônica (HUMPHREY, et al 2005). Tal situação pode ocorrer devido ao descondicionamento provocado pela dor e a mudança da característica fisiológica dos músculos multífidos, que acabam diminuindo a 
$16^{\circ}$ USIHC - Congresso Internacional de Ergonomia e Usabilidade de Interfaces Humano Computador

CINAHPA | 2017 - Congresso Internacional de Ambientes Hipermídia para Aprendizagem.

quantidade de fibras do tipo II(SPARTO et al., 1997).

\section{Conclusões}

Frequentemente os estudos científicos têm mostrado que durante contrações isométricas mantidas avaliadas por meio da EMG, há um aumento no RMS (Root meansquare) e diminuição da Frequência Média (FM), sendo indicadores de ativação neuromuscular e fadiga. A relação entre o aumento do RMS indica o recrutamento de novas fibras musculares, já a diminuição da FM demonstra uma diminuição na velocidade de condução do potencial de ação pelo acúmulo de produtos metabólicos relacionados ao processo de fadiga muscular (SANTANA, NASCIMENTO, FILHO, et al 2014; CANDOTTI et al, 2009; BASSANI, 2008; BARBOSA E GONÇALVES, 2007).

Outro fator importante relacionado à avaliação realizada nesse estudo é que atividades laborais que exigem muito esforço, acima de $60 \%$ da CIVM, podem impedir a entrada de sangue no interior do músculo, gerando lesões e adaptações, repercutindo no processo de fadiga acentuado (ROY et al, 1989; LARIVIÈRE, 2003; KRAMER, 2005).

Sendo assim, por mais que o sujeito avaliado consiga manter a força isométrica de extensão lombar em padrões normais, o estudo eletromiográfico dos músculos multifidos demonstra que já existem alterações fisiológicas e instauração acentuada de fadiga, principalmente no lado esquerdo. Essas alterações teciduais podem gerar danos irreversíveis o que afetaria o estado produtivo do indivíduo da pesquisa.

\section{BIBLIOGRAFIA}

BRASIL. Ministério do Trabalho e Emprego. Ministério da Previdência e Assistência Social. Anuário Estatístico de Acidentes do Trabalho: AEAT 2014. Brasília, 2015.

CUNHA J. M., MERINO G. S. A. D., MERINO E.
A. D. Avaliação ergonômica da extração manual de raízes de mandioca em propriedades agrícolas familiares a partir do rastreamento de movimentos 3D (X-Sens). Estudos em Design, Rio de Janeiro: v. 23, n. 3, p. 60-72, 2015.

EMBRAPA. Cultivo, processamento e uso da mandioca. Empresa Brasileira de Pesquisa Agropecuária. Ministério da Agricultura, Pecuária e Abastecimento. Embrapa Mandioca e Fruticultura. Brasília-DF, 2013. 32p.

EPAGRI. Síntese Anual da Agricultura de Santa Catarina 2013-2014. Empresa de Pesquisa Agropecuária e Extensão Rural de Santa Catarina/Centro de Socioeconomia e Planejamento Agrícola - Epagri/ Cepa, Florianópolis, SC, 131139, 208p., 2015.

FAO - Food and Agriculture Organization of the United Nations - Produzir mais com menos: Mandioca. Informe de política. Um guia para a intensificação sustentável da produção (FAO, 2013). Disponível em:

$<$ http://www.fao.org/ag/save-andgrow/cassava/pt/> Acesso em: 18 ago. 2016.

FATHALLAH F. A., MILLER B. J., MILES J. A. Low back disorders in agriculture and the role of stooped work: scope, potential, interventions, and research needs. Journal of Agricultural Safety and Health, v.14, n.2, p. 221-245, 2008.

FATHALLAH F. A. Musculoskeletal disorders in labor-intensive agriculture. Applied Ergonomics n. 41, p.738-743, 2010.

FERNANDES, C. A.; MANNRICH, G.; MERINO, G. S. A. D.; TEIXEIRA, C. S.; GONTIJO, L. A.; MERINO, E. A. D. Queixas musculoesqueléticas e a atividade da agricultura familiar. EFDeportes.com, Revista Digital. Buenos Aires - Año 19, n. 193, jun. 2014.

JUNIOR, N.G.B.; DOMENECH, S.C.; SILVA, A.C.K.; DIAS, J.A.; SAGAWA JÚNIOR, Y. Estudo comparativo da força de preensão isométrica máxima em diferentes modalidades esportivas. Revista Brasileira Cineantopometria e 


\section{$16^{\circ}$}

ERGODESIGN USIHC CINAHPA $16^{\circ}$ Ergodesign - Congresso Internacional de Ergonomia e Usabilidade de Interfaces Humano Tecnológica: Produto, Informações Ambientes Construídos e Transporte

$16^{\circ}$ USIHC - Congresso Internacional de Ergonomia e Usabilidade de Interfaces Humano Computador

CINAHPA | 2017 - Congresso Internacional de Ambientes Hipermídia para Aprendizagem.
Desempenho Humano, v.11, p. 292-98, 2009.

HUIJNEN, I. P. J. et al. Physical performance measurement in chronic low back pain: measuring physical capacity or pain-related behaviour? European Journal of Physiotherapy, v. 15, n. 3, p. 103-110, 2013.

SOARES, A.V.; JÚNIOR, CARVALHO JUNIOR J.M.; SILVA, L.; BORGES JUNIOR N.G.; DOMENECH, S. C. Valores normativos da dinamometria lombar: um teste funcional para o tronco. Anais do IV Simpósio em Neuromecânica Aplicada. p. 55-56, 2013.

SOARES, A. V., CARVALHO JUNIOR, J.M.DE, FACHINI, J., DOMENECH, S.C., BORGES JÚNIOR, N.G. Correlação entre os testes de dinamometria de preensão manual, escapular e lombar. Revista Acta Brasileira do Movimento Humano, Ji-Paraná, v. 2, n. 1, p. 65-72, 2012.

HUMPHREY AR, NARGOL AVF, JONES APC, GREENOUGH CG. The value of electromyography of the lumbar paraspinal muscles in discriminating between chroniclowback-pain suffers and normal subjects. Eur Spine J 2005, 14: 175-184.

DOUPHRATE, D. I. et al. Full-shift and taskspecific upper extremity muscle activity among US large-herd dairy parlour workers.

Ergonomics, Pages 1-13, 14 Nov 2016.

DOUPHRATE, D. I. et al. Full shift arm inclinometry among dairy parlor workers: A feasibility study in a challenging work environment. Volume 43, Issue 3, May 2012, Pages 604-613.

KRAMER M, EBERT V, KINZL L, DEHNER C, ELBEL M, HARTWIG E. Surface

electromyography of the paravertebral muscles in patients with chronic low back pain. Arch Phys Med Rehabil 2005; 86: 31-6.

LARIVIÈRE C, GRAVEL D. ARSENAULT AB, GAGNON D, LOISEL P. Muscle recovery from a short fatigue test and consequence on the reliability of EMG indices of fatigue. Eur J Appl
Physiol 2003; 89: 171-6

ROY SH, DE LUCA CJ, CASAVANT DA. Lumbar muscle fatigue and chronic lower back pain. Spine 1989; 14: 992-1001.

\section{Agradecimentos}

Os autores agradecem a Coordenação de Aperfeiçoamento de Pessoal de Nível Superior (CAPES), ao Conselho Nacional de Desenvolvimento Científico e Tecnológico (CNPq), a Fundação de Amparo à Pesquisa e Extensão Universitária (FAPEU), a Rede de Pesquisa e Desenvolvimento em Tecnologia Assistiva (RPDTA), Empresa de Pesquisa Agropecuária e Extensão Rural de Santa Catarina (EPAGRI), ao Laboratório de Instrumentação (LABIN-UDESC) e ao Núcleo de Gestão em Design e Laboratório de Design Universal da Universidade Federal de Santa Catarina NGDLDU/UFSC que viabilizaram esta pesquisa.

Realização:

